\title{
Ocular Changes in Familial Amyloidotic Polyneuropathy with Dense Vitreous Opacities
}

\author{
J. GUILHERME MONTEIRO,${ }^{1}$ A. F. F. MARTINS,${ }^{1}$ A. FIGUEIRA, ${ }^{2}$ \\ M. J. M. SARAIVA ${ }^{2,3}$ AND P. PINHO COSTA ${ }^{2}$ \\ Porto, Portugal
}

\begin{abstract}
Summary
Familial amyloid polyneuropathy (FAP) is a hereditary disease which eventually causes serious ocular problems.

Seven eyes from patients with FAP 1 were vitrectomised, and the insoluble proteins from the vitreous were purified, the amyloid protein isolated, and the prealbumin characterised with a monoclonal antibody against amyloid fibril protein.

Before surgery, visual acuity was very poor, due to abundant deposits in the vitreous, frequently attached to the posterior lens capsule. The pupil had peculiar indentations and the pupillary reflexes were abnormal. Intraocular pressure (IOP) was at the upper limit of normal. In the ocular fundus an intraretinal perifoveal gray ring was sometimes seen. Vitrectomy improved visual acuity, but the reappearance of vitreous deposits reduced it to 8.8/10 after 33.4 months, when treatment was needed for most of the eyes to control IOP. Amyloid and the mutant form of prealbumin characteristic of FAP 1, TTR Met 30, were shown to be present in the vitreous.
\end{abstract}

Several pathological situations, characterised by the deposition of fibrillar proteins with a $\beta$-pleated sheet conformation, are grouped under the term of amyloidosis. Among the primary forms of amyloidosis those with familial occurrence are especially important, particularly when associated with neurological involvement. Such is the case of familial amyloidotic polyneuropathy of the Portuguese type (FAP 1), the first to be identified and described. ${ }^{1}$ Since then familial amyloidosis has been recognised to constitute a homogeneous group of diseases with a fairly widespread distribution. Foci of the disease have been identified in such separate locations as the USA, ${ }^{2,3}$ Japan, ${ }^{4}$ Sweden, ${ }^{5}$ Ireland (Donegal county) ${ }^{6}$ and Italy, ${ }^{7}$ some of them with the same fundamental mutation as FAP 1 (Table I). Most of the hereditary amyloidoses are transmitted as autosomal dominant, are associated with variants of plasma prealbumin (transthyretin, TTR) and have peripheral neuropathy as a prominent manifestation.

Although in some forms of amyloidosis the ocular deposits of amyloid predominate in the cornea, in the TTR-dependent forms of amyloidosis they are mainly located in the vitreous. Slit lamp examination shows a gradual increase of the fibrillar appearance of the vitreous, leading to a progressive disorganisation and opacification, with the ensuing decrease of visual acuity. The frequency and magnitude of the vitreous deposits vary with

From: ${ }^{1}$ Serviço de Oftalmologia, Hospital Geral de Santo António, ${ }^{2}$ Centro de Estudos de Paramiloidose do I.N.S. and ${ }^{3}$ Departamento de Bioquímica do I.C.B.A.S.

Correspondence to: J. Guilherme Monteiro MD, FCOphth, Serviço de Oftalmologia, Hospital Geral de Santo António, 4000 Porto, Portugal. 
Table I. Characteristics of the principal variants of TTR-related forms of amyloidosis

\begin{tabular}{|c|c|c|c|c|}
\hline Name & $\begin{array}{l}\text { Position in TTR } \\
\text { molecule }\end{array}$ & Anomalous amino acid & Origin & Clinical aspects \\
\hline FAP 1 & 30 & methionine & $\begin{array}{l}\text { Portugal } \\
\text { Sweden } \\
\text { Japan } \\
\text { USA }\end{array}$ & $A N, P N, V$ \\
\hline FAP II & 84 & serine & $\begin{array}{l}\text { USA } \\
\text { Swiss }\end{array}$ & $\mathrm{AN}, \mathrm{CT}, \mathrm{HD}, \mathrm{V}$ \\
\hline $\begin{array}{l}\text { Appalachian } \\
\text { Jewish } \\
\text { Illinois/German }\end{array}$ & $\begin{array}{l}60 \\
33 \\
77\end{array}$ & $\begin{array}{l}\text { alanine } \\
\text { isoleucine } \\
\text { tyrosine }\end{array}$ & $\begin{array}{l}\text { USA } \\
\text { Israel } \\
\text { USA }\end{array}$ & $\begin{array}{c}\text { AN, CT, HD } \\
\text { AN, PN, V } \\
\text { AN, PN }\end{array}$ \\
\hline
\end{tabular}

AN-autonomic neuropathy; CT-carpal tunnel syndrome; HD-heart disease; PN-peripheral neuropathy; V-vitreous deposits. Predominant manifestation shown in bold.

the type of amyloidosis (i.e. with the mutation of TTR); even when the same mutation is involved, there are differences according to the geographical origin of the disease. Thus, vitreous deposits are a constant feature in the (small) kindred with the isoleucine 33 mutation and are usually considered much more common in the serine 84 (FAP II) than in the methionine 30 (FAP 1) mutations. ${ }^{8}$ This statement may not be totally correct since Coutinho et al found vitreous deposits in about $45 \%$ of a large series of patients. However, it is certainly true where dense deposits, leading to severe visual impairment, are concerned. In fact, only about $1 \%$ of the Portuguese patients with FAP (over 900, 500 of them still alive $^{10}$ ) needed vitrectomy, a value largely exceeded in FAP II, even if only the series of Doft $e a^{11}$ is considered. The Portuguese and Swedish foci of FAP 1 are also strikingly different in relation to the frequency of vitrectomy, surgery being much more common in the latter group, ${ }^{12,13}$ despite its smaller size (212 patients identified). ${ }^{14}$ These vitreous deposits may be, in rare instances, the only sign of disease,${ }^{15}$ but in the great majority of cases the ocular alterations are associated with systemic involvement. ${ }^{12,16}$ Consequently, the frequent association of vitreous deposits with ocular lesions similar to those seen in other organs, namely alterations of the pupillary innervation or of the ocular vessels, is not surprising. As the disease is progressive and profoundly incapacitating, the possibility of improving the visual conditions ${ }^{17}$ is of great interest.

This work describes some patients with
FAP 1 and serious vitreous amyloidosis, the results of pars plana vitrectomy, and the study of the vitreous and of the abnormal protein isolated from it.

\section{Methods}

\section{(a) Clinical study}

Seven eyes from four patients, two of each sex, were studied; one of the eyes was operated on twice, with a 3.5 year lapse. The age of the patients at the time of the first surgery was $45.6 \pm 4.4$ years (mean $\pm \mathrm{SD})$. All had FAP 1 history in the family and symptoms characteristic of the disease, as well as skin or nerve biopsy positive for amyloid. Every patient had a full ophthalmic examination before the surgery and at repeated intervals after it. The initial examination disclosed, in all patients, dense vitreous deposits, which decreased visual acuity sufficiently to warrant the need for vitrectomy; the results of visual acuity are expressed in the decimal scale.

Pars plana vitrectomy was always performed by the same surgeon, either with an Ocutome VI (Coopervision), or with a Vitreon/Surgikon (Optikon); three openings at the pars plana were used in every case. Neither during surgery nor the post-operative period were there any ocular problems. All of the infusion fluid (Ringer lactate, 100-250 ml) was collected in a flask, which was kept in ice for transport to the laboratory.

(b) Laboratory study

The material collected from three of the cases (HV1, HV2, HV3) was kept in the refrigerator at -20 degrees $C$ for $15-0.5$ months 
before being studied. After thawing, a small quantity of an amorphous substance could be seen in suspension.

Isolation of the amyloid-The fluid collected at surgery was centrifuged at 4 degrees $\mathrm{C}$ $(17,500 \mathrm{~g}, 30$ minutes $)$. The sediment was resuspended in $20 \mathrm{ml}$ of saline, buffered at pH7.2 with phosphate buffer (PBS), homogenised, and centrifuged again under the same conditions. This operation, needed to eliminate all of the vitreous soluble proteins, was repeated a second time. To eliminate the salts existing in the PBS, the sediment was twice resuspended in distilled water, homogenised as before, and centrifuged $(20,000 \mathrm{~g}, 60 \mathrm{~min})$. From the final sediments small samples were spread on glass slides and stained with Congo red, the remainder $2.3 \pm 0.2 \mathrm{mg}$ being lyophilised.

Denaturation and identification of amyloid fibrils $-0.6-0.7 \mathrm{mg}$ of each of the three final sediments were denatured with $6 \mathrm{M}$ guanidine containing dithiotreitol, ${ }^{18}$ dialysed against distilled water and lyophilised. The denatured material was studied by immunoelectrophoresis and double immunodiffusion (Ouchterlony) with commercial antiserum anti-transthyretin (TTR) and anti-human serum (Behringwerke).

Cleavuge of the TTR molecule and Western blot $-0.6-0.8 \mathrm{mg}$ of each of the three final sediments were treated with cyanogen bromide in $70 \%$ formic acid, during $24 \mathrm{~h}$, extensively dyalised against distilled water and lyophilised. ${ }^{19}$ The lyophilised material was subsequently fractioned by gel electrophoresis in $15 \%$ SDS-polyacrylamide (vertical slab gel, Hoeffer). The fractions were then transferred to nitrocellulose filters which were blocked with $5 \%$ bovine albumin and successively treated for 30 minutes with a monoclonal antibody anti-AFp (amyloid protein of FAP) prepared in the laboratory from the Centro de Estudos de Paramiloidose,$^{20}$ rabbit serum anti-mouse IgG (Amersham) and biotinilated avidin-peroxidase complexes (Amersham). The bands that fixed anti-AFp serum were then visualised with diaminobenzidine.

\section{(c) Electron microscopy}

Samples of the vitreous were fixed in $2.5 \%$ glutaraldehyde in $0.2 \mathrm{M}$ cacodylate buffer $(\mathrm{pH}$ 7.2-7.4) and post-fixed in 1\% osmium tetroxide, in the same buffer. The samples were subsequently dehydrated and embedded for electron microscopy. Ultrathin sections were studied in a transmission electron microscope after staining with uranyl acetate and lead citrate.

\section{Results}

\section{(a) Clinical study}

In two of the patients the neurological symptoms were the first manifestation of the disease, the reduction of visual acuity only appearing later (five and nine years). However, in the other two patients the first complaint was a decreased visual acuity, neurologic involvement being evident only one or two years later. The time lapse from the moment patients noticed the decreased visual acuity and (the first) ocular surgery was $3 \pm 2$ years.

Every patient had very conspicuous amyloid deposits in the vitreous, characteristically with a delicate lacy arrangement (Fig. 1), and frequently seen to attach themselves to the posterior lens capsule by means of footplates (pseudopodia lentis). In some of the patients ecography showed a posterior vitreous detachment. Owing to the opacification of the vitreous, visual acuity was very low before surgery, from hand movements to finger counting; it is to be noticed that a marked asymmetry between the two eyes was usual, even to the point of the fellow eye presenting with vision of 10/10.

Other ocular alterations were seen in most of the patients, in addition to the vitreous deposits. There was a reduction of lacrimal

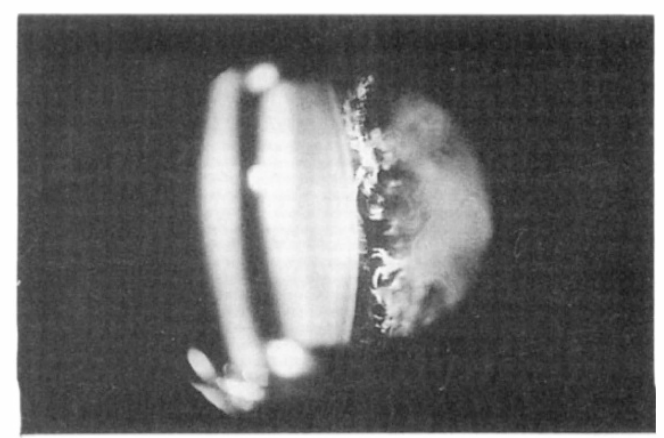

Fig. 1. Amyloid deposits in the anterior vitreous. 
secretion (Schirmer test) a decreased corneal sensitivity (measured by Cochet et Bonnet's instrument) and the cornea stained diffusely with rose bengal. The pupil usually had peculiar indentations (Fig. 2) and the pupillary reflexes were sluggish and reduced in amplitude. In the ocular fundus (as seen in the fellow eye before surgery, or in the operated eye after it) a perifoveal gray ring could be seen in some eyes (Fig. 3); slit lamp examination showed this ring to be due to an increased retinal thickness associated with decreased transparency. IOP was normal in every patient, although at its upper limit $(20.7 \pm 1.2 \mathrm{mmHg})$.

After surgery the intraocular media became transparent, and the corrected visual acuity increased to unity $(9.7 / 10$; range: $9 / 10$ $10 / 10)$. Four months after surgery there was a sudden loss of vision in one of the eyes, without any alteration of the fundus, but with loss of the superior visual field; another eye developed a cataract nine months after surgery, but recovered 10/10 visual acuity after cataract surgery. In spite of the initial result, there was a late and slowly progressive decrease of the visual acuity, owing to the renewed appearance of vitreous deposits. This led to the need for a second vitrectomy in one eye 41 months after the first operation. Thus, after $33.4 \pm 19.9$ months (range: 10-66), visual acuity was reduced to $8.8 / 10$ (range: $3 / 10$ $10 / 10$ ) or $7.6 / 10$ (range: light perception-10/ 10 ), if the eye lost for reasons independent of vitreous opacification is included. At this time most of the eyes needed medical (or surgical) treatment in order to keep IOP within normal limits $(19.2 \pm 4.4 \mathrm{mmHg})$.

(b) Laboratory study

The study of the material collected at vit-

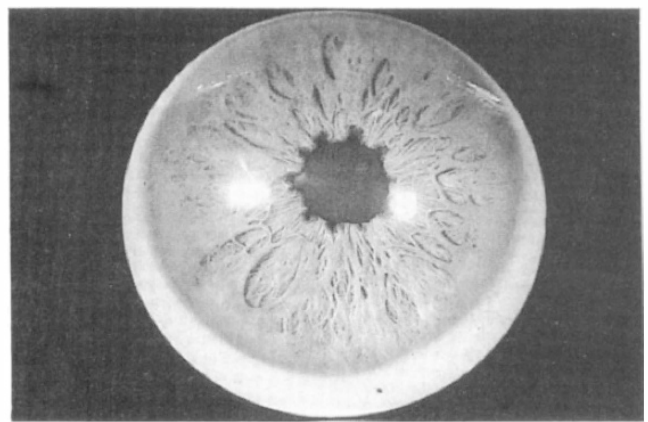

Fig. 2. Iris-indentations of the pupillary border. rectomy showed an amorphous and insoluble sediment which had the green birefringence characteristic of amyloid when smears prepared from these sediments were coloured by Congo red and examined under polarised light microscopy. It was also shown that, after denaturation, the material obtained from the vitreous reacted with commercial serum antihuman TTR, and that it was constituted by a protein with electrophoretic and immunoreactivity similar to those shown by the protein AFp, a fundamental component of amyloid fibrils isolated from different organs of patients with FAP $1 .{ }^{18}$ Finally, the results obtained by the Western blot confirmed the presence of the molecular form of TTR characteristic of the Portuguese type of FAP, TTR Met 30.

\section{(c) Electron microscopy}

When the vitreous was examined on a transmission electron microscope after staining with uranyl acetate-lead citrate, randomly distributed non-branching fibrils were seen

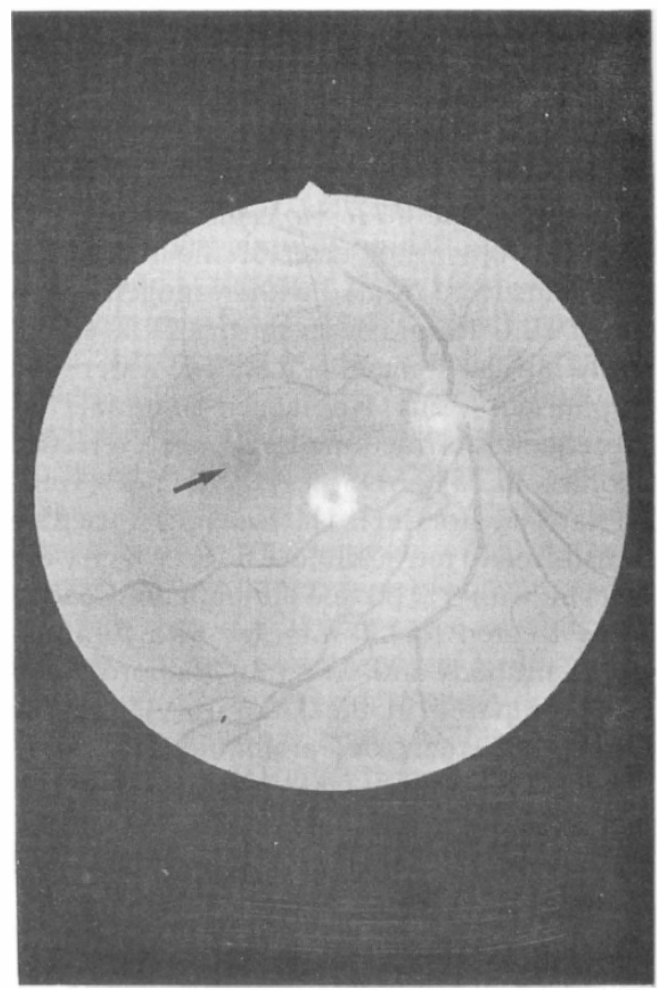

Fig. 3. Eye fundus of patient with FAP, with perifoveal ring (arrow). 
(Fig. 4), although in some places the individual fibrils were arranged as parallel arrays. On higher magnification the individual fibrils could be seen to have diameters ranging from $5 \mathrm{~nm}$ to $10 \mathrm{~nm}$, some of them showing a transverse striation with a periodicity of about 5-15 nm (Fig. 4, inset). These characteristics are those usually ascribed to amyloid.

\section{Discussion}

Vitreous opacities, with accompanying decrease of visual acuity, are quite frequent in FAP 1, although in many of them the opacities were relatively discrete up to an advanced stage of the disease. The present work confirms, by a biochemical study, that these opacities are essentially composed by amyloid deposits; the results obtained by electron microscopy are in agreement with the biochemical study, since the characteristics of the deposits (random distribution of the fibrils, fibril diameter and periodicity of the cross striation) are those usually ascribed to amyloid. Furthermore, it was shown that these deposits contain TTR Met 30 (molecular form of TTR obtained by substituting methionine for the valine in position 30 of the peptide), ${ }^{21}$ thus being identical to the deposits seen in other organs of patients with FAP 1.

In the present series of patients, all of them with confirmed FAP 1, the age at the time of vitrectomy was much lower than in the series of Sandgren et al. ${ }^{12}$ This is not completely unexpected, since the patients studied by these authors belong to a nucleus of FAP (north of Sweden) that, although with the same fundamental mutation as in the Portuguese nucleus, show the initial symptoms at an age of about 24 years higher than the Portuguese patients. ${ }^{14}$

When only the immediate results of vitrectomy are considered, they are remarkably good, visual acuity increasing from finger counting to unity. This is the result usually obtained in vitreous amyloidosis, either in isolated patients, ${ }^{22}$ or in series. ${ }^{11,12}$ Our results are very similar to those of Sandgren et al, ${ }^{12}$ although the follow-up by these authors has

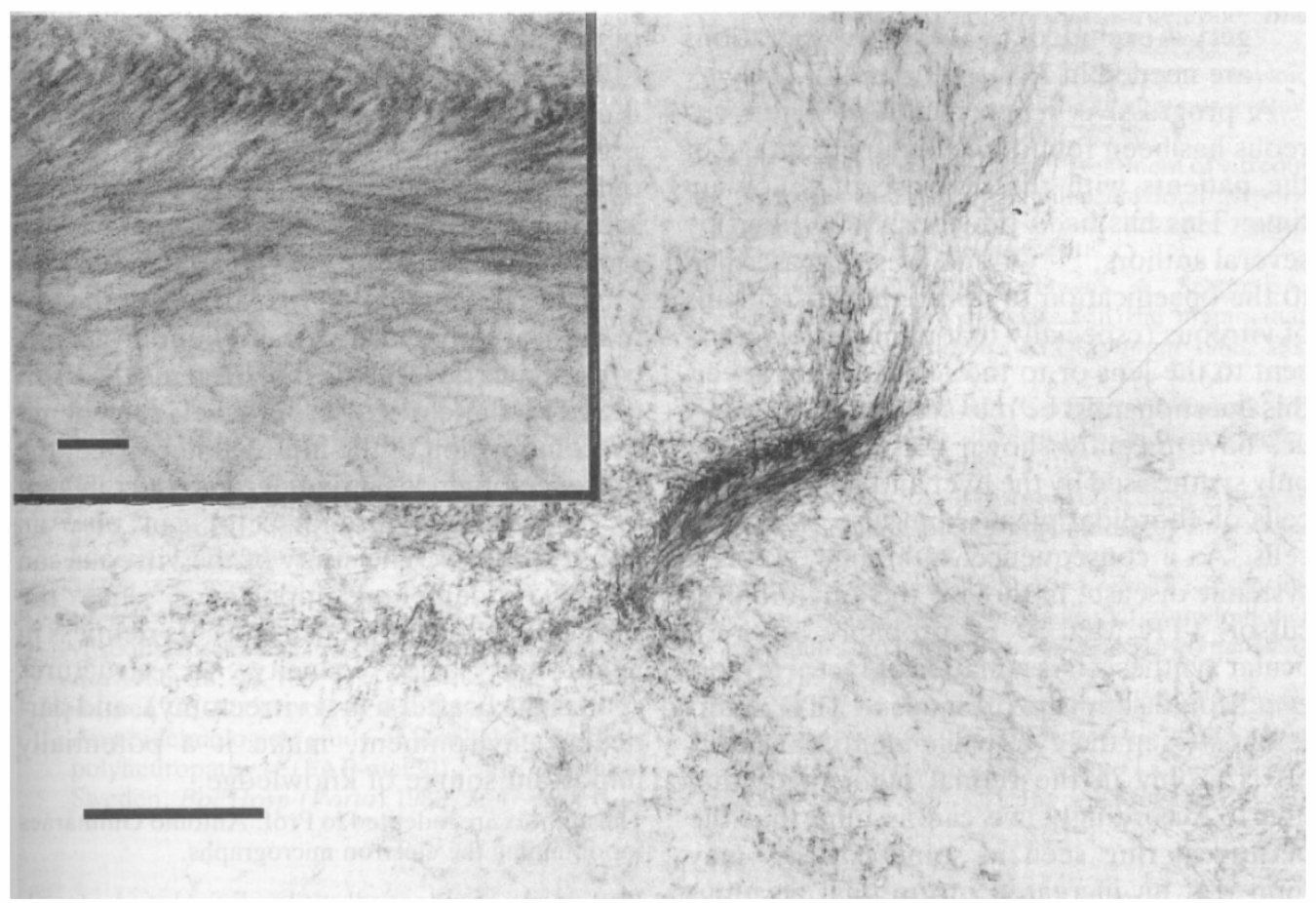

Fig. 4. Transmission electron micrograph of an amyloidotic vitreous (uranyl acetate-lead citrate) showing randomly distributed and a parallel array of amyloid fibrils $(\times 25000 ;$ bar $=0.5 \mu \mathrm{m})$. Inset-higher magnification $(\times 100000 ;$ bar $=0.1 \mu \mathrm{m})$ showing fibrils ranging from $5 \mathrm{~nm}$ to $10 \mathrm{~nm}$ in diameter. 
been much shorter than ours (15 vs 33 months); even the existing slight difference, both in the immediate and late results, can probably be attributed to non-vitreous causes, namely cataracts or age-related macular degeneration, a possibility that we must bear in mind considering the different age distribution of the two groups. On the other hand, the series of Doft et al, ${ }^{11}$ with a follow-up similar to ours, shows a final visual result significantly worse $(\mathrm{p}<0.025$; Student $t$-test) than the one obtained in the present series. If this difference cannot be attributed to a longer follow-up, the age difference is again a possible cause. But two other causes can also be involved:

(a) the mutation and molecular variant of TTR are expected to be different from those in FAP 1, since most of the 17 patients presumably come from the United States (six of the nine surgeons were from ophthalmic centres in this country), from different backgrounds;

(b) the high incidence of complications, both during and after surgery (if cataract surgery is excluded, two or more operations are needed in $33 \%$ of the eyes).

A progressive reopacification of the vitreous has been found in a high percentage of the patients with the increase of follow-up time. This has been previously described by several authors, ${ }^{11,12,23,24}$ and is usually ascribed to the opacification of non-removed remains of vitreous (especially that immediately adjacent to the lens or to the retina). ${ }^{16}$ However, this question must be reexamined. Martone et $a l^{25}$ have recently shown that TTR was not only synthesised by the liver and the epithelial cells of choroidal plexus, but also by retinal cells. As a consequence, although FAP is a systemic disease, in the eye the amyloid precursor TTR Met 30 is, probably, of local ocular synthesis. As a matter of fact, Herbert et $a l^{26}$ could show the presence of TTR at different sites in the eye (while identifying TTR mRNA only in the retinal pigment epithelium). Accordingly, we can assume that the perifoveal ring seen in some patients may represent an increased intraretinal accumulation of the mutant form of TTR, either synthesised in the retinal pigment epithelial cells and transported into the neuroretina, or synthesised by retinal Müller cells. On the other hand, the dense attachment of vitreous strands to the lens can suggest that the lens epithelium is also able to synthesise TTR. Thus, local synthesis could then be involved in the progressive reopacification of the vitreous seen after vitrectomy.

The other ocular aspects seen in these patients were not totally unexpected. The scalloped pupil has already been described in the princeps description of the disease, ${ }^{1}$ and is probably related to autonomic disfunction of the parasympathetic nervous system, as suggested by Lessell et al..$^{27}$ This same reason is the probable cause of the decreased lacrimal secretion, while the reduced corneal sensitivity is dependent on the infiltration of the sensory nerves to the cornea. Both of these signs are not exclusive to the patients with dense vitreous deposits, since they were previously found in series of patients with mild vitreous involvement. ${ }^{28,29}$ Finally, the increased IOP, a major cause of loss of vision in patients with FAP 1 , is certainly related to the deposition of amyloid in the angle of the anterior chamber. ${ }^{16}$

The pathogenesis of FAP raises some intriguing questions. Why, being the amyloid precursor synthesised from birth onwards, only after 20,30 , or even after 50 to 70 years are the abnormal deposits formed? Which factor(s) leads to the polymerisation of that precursor as amyloid fibrils? In fact, if the formation of amyloid is certainly under genetic control, it is no less true that local mechanisms (namely, the corticosteroid level, the chemical composition of the intercellular space, the presence of glucosaminoglycans, of collagen, or of basal membranes, etc) can play an important role. The study of the vitreous can be of fundamental importance since the simple structure of the vitreous, its richness in hyaluronic acid, paucity in structures (particularly after a first vitrectomy), and particular environment, make it a potentially important source of knowledge.

The authors are indebted to Prof. António Guimarães for obtaining the electron micrographs.

Key words: biochemical study, clinical study, familial amyloidotic polyneuropathy, FAP, vitrectomy, vitreous amyloidosis. 


\section{References}

${ }^{1}$ Andrade C: A peculiar form of peripheral neuropathy: familiar atypical generalized amyloidosis with special involvement of the peripheral nerves. Brain 1952, 95: 408-27.

${ }^{2}$ Falls HF, Jackson JH, Carey JG, Rukavina JG, Block WD: Ocular manifestations of hereditary primary systemic amyloidosis. Arch Ophthalmol 1955, 54: 660-4.

${ }^{3}$ Wallace MR, Dwulet FE, Conneally PM, Benson MD: Biochemical and molecular genetic characterisation of a new variant prealbumin associated with hereditary amyloidosis. J Clin Invest 1986, 78: 6-12.

${ }^{4}$ Araki S, Mawatari S, Ohta M, Nakajima A, Kuroiwa Y: Polyneurotic amyloidosis in a Japanese family. Arch Neurol 1968, 18: 593-602.

${ }^{5}$ Andersson R and Kassman T: Vitreous opacities in primary familial amyloidosis. Acta Ophthalmol (Copenh) 1968, 46: 441-7.

${ }^{6}$ Dervan P, Kelly P, Staunton H: Amyloid neuropathy-a cluster of five cases. Can J Neurol Sci 1983, 10: 140(A).

${ }^{7}$ Salvi F, Ferlini A, Plasmati R, Romeo G, Bergamini L, Rovette P, Verri AP, Marbini A, Costa PP, Saraiva MJM, Ambrosetto G, Tassinari CA: Studio delle famiglie italiane con ricorrenza di polineuropatia amiloidotica familiare (FAP). Bol Hosp (Porto) 1988, 3: 43-6.

${ }^{8}$ Benson MD and Wallace MR: Amyloidosis. In Scriver CR, Beaudet A, Sly W, Valle D, eds. The metabolic basis of inherited diseases, New York: McGraw-Hill 1988; 2439-2460.

${ }^{9}$ Coutinho P, Martins da Silva A, Lopes Lima J, Resende Barbosa A: Forty years of experience with type 1 amyloid neuropathy. Review of 483 cases. In Glenner GG, Costa PP, Freitas AF, eds. Amyloid and amyloidosis, Amsterdam: Excerpta Medica 1980; 88-98.

${ }^{10}$ Coutinho P e Ribeiro I: A forma tardia da polineuropatia amiloidótica familiar. Bol Hosp (Porto) 1988, 3: 57-62.

${ }^{11}$ Doft BH, Machemer R, Skinner R, Buettner H, Clarkson J, Crock J, McLeod D, Michels R, Scott J, Wilson D: Pars plana vitrectomy for vitreous amyloidosis. Ophthalmology 1987, 94: 607-11.

${ }^{12}$ Sandgren O, Stenkula S, Dedorsson I: Vitreous surgery in patients with primary neuropathic amyloidosis. Acta Ophthalmol (Copenh) 1985, 63: 383-8.

${ }^{13}$ Sandgren O, Westermark P, Stenkula S: Relation of vitreous amyloidosis to prealbumin. Ophthalmic Res 1986, 18: 98-103.

${ }^{14}$ Holmgren G, Andersson R, Sandgren O, Steen L: An epidemiological study of familial amyloidotic polyneuropathy (FAP-met30) in northern Sweden. Bol Hosp (Porto) 1988, 3: 47-52.
${ }^{15}$ Ferry AP and Lieberman TW: Bilateral amyloidosis of the vitreous body. Arch Ophthalmol 1976, 94: 982-91.

${ }^{16}$ Schwartz MF, Green WR, Michels RG, Kincaid MC, Fogle J: An unusual case of ocular involvement in primary systemic non-familial amyloidosis. Ophthalmology 1982, 89: 394-401.

${ }^{17}$ Machemer R and Norton EWD: A new concept for vitreous surgery. 3. Indications and results. $\mathrm{Am} \mathrm{J}$ Ophthalmol 1972, 74: 1034-56.

${ }^{18}$ Costa PP, Figueira AS, Bravo FR: Amyloid fibril protein related to prealbumin in familial amyloidotic polyneuropathy. Proc Natl Acad Sci USA 1978, 75: 4499-503.

${ }^{19}$ Saraiva MJM, Melhus H, Rego K, Costa PP, Peterson PA, Goodman DS: Genetic studies on a human plasma transthyretin (prealbumin) variant associated with familial amyloidotic polyneuropathy. In: Peeters H, ed. Protides of the biological fluids, Oxford: Pergamon Press 1985; vol 33, 127-30.

${ }^{20}$ Costa PMP, Saraiva MJM, Costa PP: Anticorpos monoclonais anti-TTR (Met30). $_{\text {Bol Hosp (Porto) }}$ 1988, 3: 127-31.

${ }^{21}$ Saraiva MJM, Goodman DS, Costa PP, Canfield RE, Birken S: Presence of an abnormal transthyretin (prealbumin) in Portuguese patients with familial amyloidotic polyneuropathy. Clin Res 1983, 31: S33.

${ }^{22}$ Trepsat C et Boeda S: Un nouveau cas d'amylose vitréenne avec confirmation ultrastructurale. Bull Mem Soc Fr Ophthalmol 1986, 97: 119-23.

${ }^{23}$ Irvine AR and Char DH: Recurrent amyloid involvement in the vitreous body after vitrectomy. Am J Ophthalmol 1976, 82: 705-8.

${ }^{24}$ Giora T, Gad K, Mordechai P: Treatment of vitreous opacities in a case of familial amyloidotic polyneuropathy by vitreous surgery. Metabol Pediatr Ophthalmol 1981, 5: 105-8.

${ }^{25}$ Martone RL, Herbert J, Dwork A, Schon EA: Transthyretin is synthesised in the mammalian eye. Biochem Biophys Res Commun 1988, 151: 905-12.

${ }^{26}$ Herbert J, Martone RL, Cavallaro T, Dwork AJ, Schon EA: Intraocular synthesis of transthyretin. Arq Med (Porto) 1989, 3: 193, A28.

${ }^{27}$ Lessell S, Wolf PA, Benson MD, Cohen AS: Scalloped pupils in familial amyloidosis. $N$ Engl J Med 1975, 293: 914-15.

${ }^{28}$ Martins F, Gomes M, Leite V e Freitas C: A sensibilidade corneana na polineuropatia amiloidótica familiar tipo português. Rev Soc Port Oftal 1990, 16: (in press).

${ }^{29}$ Martins F, Gomes A e Sepúlveda E: Alterações oculares clínicas da polineuropatia amiloidótica familiar tipo português (PAF tipo 1). Rev Soc Port Oftal 1990. 16: (in press). 